\title{
Results of an Observational Study of Child Care Centers in Pennsylvania: Varying Approaches to Health and Safety
}

\author{
Frances M. Nadel ${ }^{1}$, Susan S. Aronson ${ }^{2}$, Angelo P. Giardino ${ }^{*}, 3$, Heather Rivers ${ }^{4}$, Amy Requa $^{5}$ and \\ Kathy N. Shaw ${ }^{1}$
}

\author{
${ }^{I}$ The Children's Hospital of Philadelphia, $34^{\text {th }}$ Street and Civic Center Boulevard, Philadelphia, PA 19104-4399, USA \\ ${ }^{2}$ Early Childhood Education Linkage System: (ECELS), PA Chapter - AAP, 1400 N. Providence Road, Rose Tree \\ Corporate Center II - Suite 3007, Media, PA 19063, USA \\ ${ }^{3}$ Texas Children's Health Plan, Baylor College of Medicine, 2450 Holcombe, Suite 34L, Houston, Texas 77021, USA \\ ${ }^{4}$ ECELS - Healthy Child Care Pennsylvania, 1400 N. Providence, Suite 3007, Media, Pennsylvania, 190063, USA \\ ${ }^{5}$ ICF International, 9300 Lee Highway, Fairfax, VA 22031-1207, USA
}

\begin{abstract}
Objective: Exploring several health and safety practices in child care centers (CCCs) in Pennsylvania (PA).
Design and Methods: A prospective observational study of a convenience sample of CCCs was done. On-site evaluations included direct observation of hand washing behaviors, infant sleep position, playground equipment safety, and an assessment of safety policies.

Results: Evaluations were done at 134 sites. The director's median time in her current position was 2.5 years; $32 \%$ of the providers worked at the site less than one year. Sixteen $(12 \%)$ sites had consulted a doctor on health policy development. Of 114 food preparation or consumption observations, $88(77 \%)$ of the adults and $100(92 \%)$ of the children washed their hands; and, of 181 diapering or toileting observations, $78(83 \%)$ of the adults and $103(95 \%)$ of the children washed their hands. Staff placed $67 \%$ of infants on their backs for sleep. Safe playground surfacing was observed surrounding $10(21 \%)$ indoor and $52(57 \%)$ outdoor equipment areas. Overall, suburban, non-profit, parent funded centers performed better than urban, for profit, state funded centers-except for sleep positioning when the opposite association was observed.

Conclusion: Many CCCs lack adequate health and safety practices especially those sites that were urban, for profit, or were predominately state funded. Improving the training of staff, updating or increasing comprehensive and accurate policies, and obtaining input from skilled health professionals may improve safety in CCCs.
\end{abstract}

Keywords: Child care, child care centers, hand hygiene, infant sleep position, safety, special health care needs, health education.

\section{INTRODUCTION}

Nationally, nearly two-thirds of children are in some form of out-of-home child care before entering formal school $[1,2]$. Many of these children spend a large part of their active day in a child care center (CCC) [3, 4]. See Tables $\mathbf{1 a}$ and $\mathbf{1 b}$.

Many states, including Pennsylvania are adopting Early Learning Standards with references to health, acknowledging that health and safety are key components for ensuring school readiness $[5,6]$. Unfortunately, mediocre or poor care is often the norm [7]. Although the rate of injury in CCCs is lower than in the child's home, preventable injuries occur in these child-focused settings. In quality studies, health practices receive the lowest scores $[7,8]$. National organizat-

*Address correspondence to this author at the Texas Children's Health Plan, 2450 Holcombe Boulevard, Suite 34L, Houston, TX 77021, USA; Tel: 832828-1216; Fax: 832-825-8765; E-mail: apgiardi@texaschildrenshospital.org ions, including the American Academy of Pediatrics (AAP), the American Public Health Association and the Maternal and Child Health Bureau (MCHB), Head Start and accrediting early education associations, have published health and safety standards [9-11]. However, compliance has been difficult for programs to achieve $[12,13]$. Some encouraging studies suggest that teaching designated staff to be Child Care Health Advocates, providing input from a health professional through child care health consultation, and focused environmental modifications can improve health and safety performance [14-16].

Nearly 4000 regulated CCCs provide non-residential care for children in Pennsylvania (PA). State agencies annually inspect these centers for regulatory compliance. The state requires that at least one person with current first aid training must be in the facility at all times. The regulations related to emergencies also require fire drills, emergency contact information for children, an operable telephone, a process for handling emergency medical care, and some medication administration procedures. Each site must have 
information regarding a child's health insurance and a pertinent medical plan in an emergency. Since 1989, needs assessments and interventions to improve health and safety in Pennsylvania's early education and child care programs have been undertaken by a health and safety-promotion program of the state chapter of the AAP, the Early Childhood Education Linkage System (ECELS) (please see: www.ecels-healthychildcarepa.org/). ECELS uses state and private funding to arrange training and technical assistance in health and safety for all Pennsylvania early education and child care programs.

We performed an assessment of the health and safety practices of a convenience sample of CCCs in relation to site characteristics in several regions served by ECELS within PA. Consistent with some of the priorities recognized by leading national organizations concerned with quality in early education and child care, the areas assessed included 1) health practices related to first aid and emergency care policies, 2) hand washing behaviors for staff and children, 3) infant sleep position, and, 4) indoor and outdoor gross motor play safety.

Table 1a. Parental vs Non-Parental Care

\begin{tabular}{|c|c|c|c|c|}
\hline \multirow[b]{2}{*}{ Characteristic } & \multicolumn{2}{|c|}{ Parental Care } & \multicolumn{2}{|c|}{ Non-Parental Care* } \\
\hline & 2001 & 2005 & 2001 & 2005 \\
\hline Total & 38.8 & 39.2 & 61.2 & 60.8 \\
\hline \multicolumn{5}{|l|}{ Age } \\
\hline Ages $0-2$ & 48.0 & 49.3 & 52.0 & 50.7 \\
\hline $\begin{array}{l}\text { Ages 3-6, not yet } \\
\text { in kindergarten }\end{array}$ & 26.3 & 23.6 & 73.7 & 73.7 \\
\hline \multicolumn{5}{|l|}{ Poverty status } \\
\hline Below $100 \%$ & 45.3 & 49.2 & 54.7 & 50.8 \\
\hline $100-199 \%$ & 46.3 & 47.2 & 53.7 & 52.8 \\
\hline $\begin{array}{l}200 \% \text { poverty } \\
\text { and above }\end{array}$ & 32.7 & 31.6 & 67.3 & 68.4 \\
\hline \multicolumn{5}{|c|}{ Race \& Hispanic origin } \\
\hline $\begin{array}{l}\text { White, non- } \\
\text { Hispanic }\end{array}$ & 38.4 & 37.2 & 61.6 & 62.8 \\
\hline $\begin{array}{l}\text { Black, non- } \\
\text { Hispanic }\end{array}$ & 26.1 & 30.1 & 73.9 & 69.9 \\
\hline Asian & 43.2 & 43.5 & 56.8 & 56.5 \\
\hline Hispanic & 52.0 & 50.5 & 48.0 & 49.5 \\
\hline \multicolumn{5}{|l|}{ Region } \\
\hline Northeast & 35.8 & 38.3 & 64.2 & 61.7 \\
\hline South & 37.0 & 38.0 & 63.0 & 62.0 \\
\hline Midwest & 37.0 & 36.7 & 63.0 & 63.3 \\
\hline West & 45.5 & 43.9 & 54.5 & 56.1 \\
\hline
\end{tabular}

*Some children participate in more than one type of non-parental care arrangement. Thus, details do not show the total percentage of children in non-parental care.

Adapted from ChildStats.gov. Forum on Child and Family Statistics. Child Care: Percentage of Children Ages 0-6, not yet in Kindergarten by Type of Care Arrangement and Child and Family Characteristics, 1995, 2002, 2005. www.childstats.gov/americaschildren/tables/fam3b.asp [1].
Table 1b. Type of Non-Parental Arrangement

\begin{tabular}{|c|c|c|c|c|c|c|}
\hline \multirow[b]{3}{*}{ Characteristic } & \multicolumn{4}{|c|}{ Care in a Home } & \multirow{2}{*}{\multicolumn{2}{|c|}{$\begin{array}{c}\text { Center Based } \\
\text { Program }\end{array}$}} \\
\hline & \multicolumn{2}{|c|}{$\begin{array}{c}\text { By a } \\
\text { Relative }\end{array}$} & \multicolumn{2}{|c|}{$\begin{array}{c}\text { By a } \\
\text { Non-Relative }\end{array}$} & & \\
\hline & 2001 & 2005 & 2001 & 2005 & 2001 & 2005 \\
\hline Total & 23.1 & 22.3 & 16.3 & 13.9 & 33.4 & 36.1 \\
\hline \multicolumn{7}{|l|}{ Age } \\
\hline Ages $0-2$ & 23.3 & 22.0 & 18.0 & 15.6 & 16.5 & 19.6 \\
\hline $\begin{array}{l}\text { Ages 3-6, not yet } \\
\text { in kindergarten }\end{array}$ & 22.7 & 22.7 & 14.0 & 11.7 & 56.3 & 57.1 \\
\hline \multicolumn{7}{|l|}{ Poverty status } \\
\hline Below $100 \%$ & 27.4 & 23.3 & 10.6 & 8.0 & 26.9 & 28.3 \\
\hline $100-199 \%$ & 22.5 & 23.5 & 12.6 & 9.3 & 27.8 & 29.4 \\
\hline $\begin{array}{l}200 \% \text { poverty } \\
\text { and above }\end{array}$ & 21.4 & 21.4 & 20.5 & 18.3 & 38.7 & 42.2 \\
\hline \multicolumn{7}{|c|}{ Race \& Hispanic origin } \\
\hline White, non-Hispanic & 20.3 & 21.0 & 18.7 & 17.0 & 35.1 & 37.8 \\
\hline Black, non-Hispanic & 34.6 & 27.7 & 12.9 & 10.2 & 40.2 & 43.9 \\
\hline Asian & 22.9 & 21.3 & 8.7 & 9.0 & 34.1 & 37.0 \\
\hline Hispanic & 22.9 & 21.2 & 11.8 & 10.4 & 20.7 & 25.2 \\
\hline \multicolumn{7}{|l|}{ Region } \\
\hline Northeast & 27.0 & 21.0 & 15.9 & 15.1 & 35.5 & 37.9 \\
\hline South & 22.9 & 22.3 & 14.1 & 11.1 & 36.4 & 38.8 \\
\hline Midwest & 22.0 & 23.8 & 21.1 & 18.8 & 33.8 & 33.5 \\
\hline West & 21.4 & 21.8 & 14.9 & 12.6 & 27.1 & 33.1 \\
\hline
\end{tabular}

*Center-based programs include day care centers, pre-kindergartens, nursery schools, Head Start programs, and other early childhood education programs.

Adapted from ChildStats.gov. Forum on Child and Family Statistics. Child Care: Percentage of Children Ages 0-6, not yet in Kindergarten by Type of Care Arrangement and Child and Family Characteristics, 1995, 2002, 2005. www.childstats.gov/americaschildren/tables/fam3b.asp [1].

\section{METHODS}

This was a prospective observational study of a convenience sample of CCCs across the southern half of Pennsylvania, identified as three regions, Southeast (SE), South-central (SC) and Southwest (SW) which correspond to the metropolitan areas in and around Philadelphia, York and Pittsburgh, respectively. Data collection included a telephone interview with the center director and a site visit of each center by a trained evaluator during the year 2000 .

Center Characteristics: Centers were categorized based on their metro status (urban, suburban, rural), profit designation (for-profit, not-for-profit), and source of funding (state-funded, parent-funded). Metro and profit status was determined by the center's director, during the telephone interview. In order to stratify centers based on predominance of state subsidy versus predominance of parent out-of-pocket support, the authors decided a priori that centers with $2 / 3$ of their funding derived from state subsidy to the center were state funded and those with $2 / 3$ of their funding derived from the collection of fees paid out-ofpocket by the parents were parent funded. 


\section{Center Recruitment}

ECELS staff coordinated center recruitment. An insert in the statewide newsletter Health Link, mailed quarterly to regulated child care facilities by ECELS, invited CCCs in the Philadelphia, York, and Pittsburgh areas including their surrounding counties to participate in the study designated as SE, SC and SW respectively. These regions were selected because ECELS had pre-existing relationships to draw on for recruitment, training and administration and because the density of child care centers in these areas made the project feasible with the resources available. Additionally, regional child care leaders and community nurses from the Pennsylvania Department of Health helped recruit centers through their contacts and relations with local programs.

The project staff from ECELS contacted interested program directors by telephone to explain the project and enroll willing centers. Only CCCs that were regulated and certified to operate as child care centers were eligible. Sites that do not fall under the same child care center state regulations, such as home based facilities (family child care homes) and part-day nursery schools were excluded. The state has different regulations and different approaches to oversight of these facilities. Participating sites received a gift of Risk Watch ${ }$, a National Fire Prevention Association preschool child safety curriculum [17].

\section{Evaluation}

We assessed CCCs using a two step process organized by three separate but related multi-page assessment tools. First, each CCC director was interviewed on the telephone by a designated member of the project staff from ECELS about site demographics and safety policies. This telephone interview consisted of 59 items and focused on center demographics. Second, a trained evaluator did an on-site assessment. The on-site assessment tool had 72 items that documented policies that were reviewed and an additional 54 items that dealt with the actual on-site observations of behaviors; all items were selected and updated from a previously used tool guided by the national health and safety performance standards. The standards chosen for the onsite assessment were selected from the subset published by the National Resource Center for Health and Safety in Child Care in Stepping Stones, which includes the national standards from Caring for Our Children, chosen by a panel of national experts as those most likely to prevent disease, disability and death in out-of-home childcare $\left(2^{\text {nd }}\right.$ edition available at www.nrckids.org) [18]. The on-site assessment included direct observation of hand washing behaviors of staff and children, infant sleep position, playground equipment safety, and verification of the presence and adequacy of safety policies and plans for the care of children with special needs as well as the basic elements in the then current $\left(3^{\text {rd }}\right)$

Table 2a. Hand Washing Behaviors for Staff and Children

\begin{tabular}{|c|c|}
\hline Observation & Measurement \\
\hline $\begin{array}{l}\text { Observe at least one area where at least one adults and/or children might wash their hands before performing the } \\
\text { monitored activities: }\end{array}$ & Number Observed \\
\hline \multicolumn{2}{|l|}{ Adults and children might wash their hands before they handle food } \\
\hline Number of locations where evaluator saw adult or child hand washing related to food handling & Locations \\
\hline Number of adults observed for hand washing & Adults \\
\hline Number of adult or child instances observed just before a food-related activity, which requires hand washing & $\begin{array}{l}\text { Times when an adult or child } \\
\text { should have washed }\end{array}$ \\
\hline Number of instances when an adult or child washed his/her hands before a food-related activity & $\begin{array}{l}\text { Times when an adult or child } \\
\text { washed }\end{array}$ \\
\hline Number of children observed for hand washing before food-related activities & Number of children \\
\hline Number of times when a child washed with running water before a food-related activity & Times when a child washed \\
\hline \multicolumn{2}{|l|}{ Children: toilet-related hand washing } \\
\hline Number of locations where evaluator observed toilet-related hand washing by children & Locations \\
\hline Number of children observed for hand washing after toileting & Number of children \\
\hline Number of child instances when a child was observed toileting, and therefore should have washed his/her hands & $\begin{array}{l}\text { Times when a child should have } \\
\text { washed }\end{array}$ \\
\hline Number of instances when a child washed hands after toileting (If none, skip to section on Infant and Toddler) & Times when a child washed \\
\hline Number of times when children washed with running water (not in a common bucket or by hand wiping) after toileting & Times when a child washed \\
\hline \multicolumn{2}{|l|}{ Adults: observations of hand washing after diapering } \\
\hline Number of locations where evaluator looked at adult hand washing after diaper changing & Locations \\
\hline Number of adults observed doing diaper changing & Number of adults \\
\hline $\begin{array}{c}\text { Number of adult instances observed just after a child's diaper was changed, which required hand washing before } \\
\text { beginning another activity }\end{array}$ & $\begin{array}{l}\text { Times when an adult should } \\
\text { have washed }\end{array}$ \\
\hline Number of instances when an adult washed his/her hands after diaper changing & Times when an adult washed \\
\hline
\end{tabular}


Table 2b. Indoor and Outdoor Gross Motor Play Safety

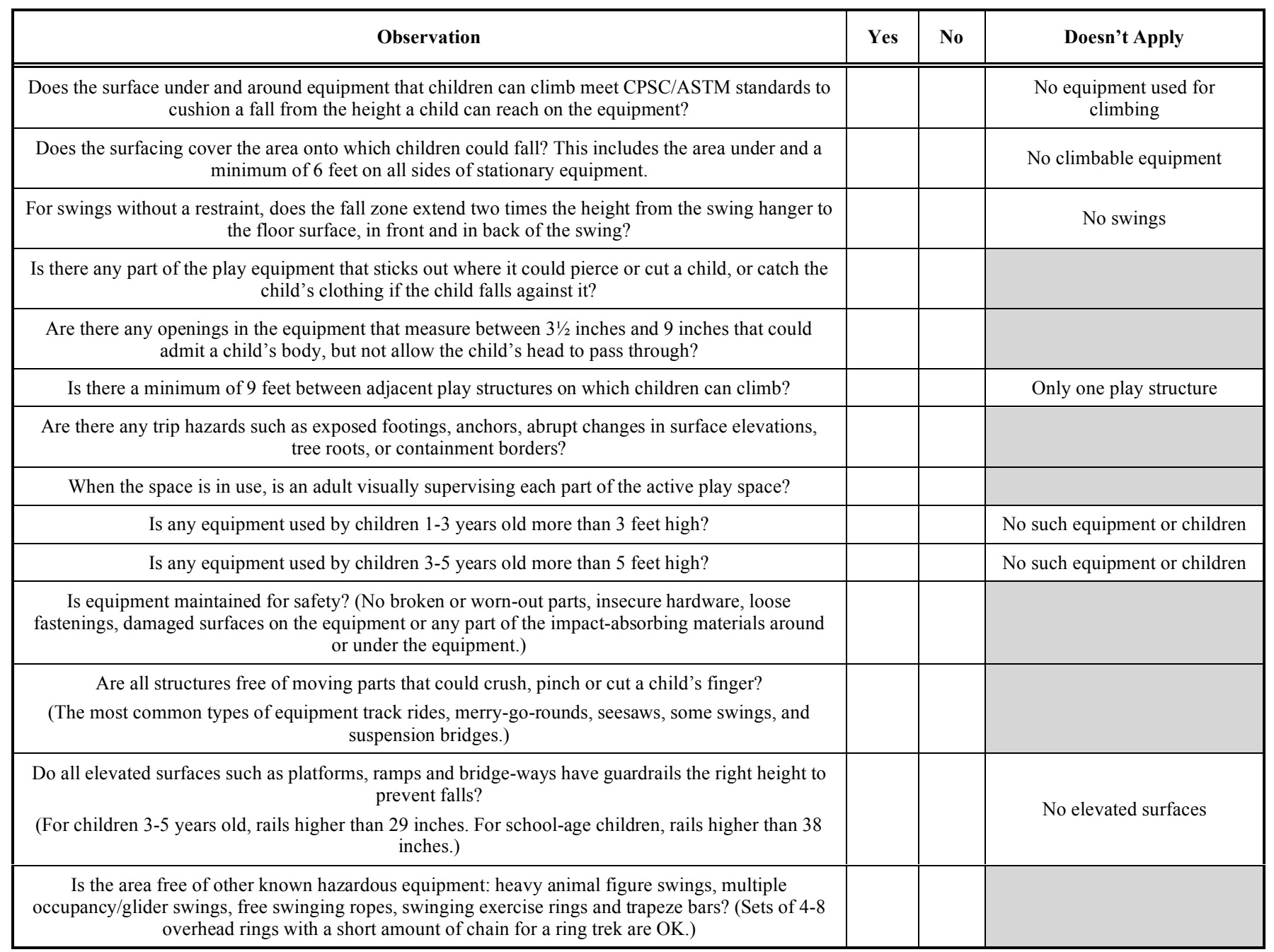

edition of a published set of Model Child Care Health Policies [19]. See Tables $\mathbf{2 a}$ and $\mathbf{2 b}$ for examples of on site observation tools related to hand washing and playground safety.

Inter-rater reliability was checked in several field trials in which simultaneous administration by at least two evaluators of the on site assessment tool and interview were piloted at sites not included in the data analysis. Items with less than moderate agreement ( $<60 \%$ inter-observer agreement) were not included in the results [20]. A data manager transferred the data from the assessment tool forms into a data base for scoring and analysis. On-site Evaluators: ECELS staff recruited nurses, Emergency Medical Personnel (EMP) and other health professionals to volunteer as on-site evaluators. The decision to seek volunteer evaluators was due to the funding limitations for this project. The logistics of training of the evaluators in different regions of Pennsylvania required alternative training formats. Evaluator training consisted of a 2 hour session; volunteers participated in this session as either part of a one day in person workshop that also included health care consultant training or as a teleconference focused only on evaluator training led by the same ECELS staff. Though the format was different, the content related to the evaluator role covered in these different formats was identical. Evaluators called one identified member of the ECELS project staff while on-site for just-in-time mentoring when they encountered any situation that seemed challenging such as a director who was unavailable, or a facility that did not keep copies of its policies on site. Some volunteers had schedule conflicts that made it difficult for them to arrange to do their share of the evaluations; therefore, additional financial resources were obtained to recruit additional health professionals who were trained as evaluators using the same approach used to train the volunteer evaluators and then paid a small fee to perform the evaluations.

\section{Descriptive Analyses}

On site specific variables consisted of frequencies for categorical variables, such as sleep position, and mean, median, range, standard deviation and 95\% confidence intervals for continuous variables, such as number of years as a director. A stratified analysis was done to assess differences in center practice and policy based on the following subgroups: 1) metro status 2) profit designation, and 3) source of funding. There were an insufficient number (19 or $14 \%$ ) of rural sites to make comparisons to the urban and suburban sites meaningful [21], and therefore we focused on urban and suburban differences. Chi-square analysis was done to explore the relationship of site 
demographics on various discretely observed, on-site practice outcomes. Inter-observer agreement was calculated using the Kappa coefficient. Stata 6.0 was used for all data analysis.

\section{RESULTS}

Although 310 CCCs were initially interested in participating from across the state of PA, a convenience sample comprised of 134 sites were chosen from the SE, SC and SW geographic areas based on the feasibility of conducting the evaluations within a geographic area and on the number of sites that evaluators could visit in each area.

For each of the on-site evaluations in which inter-rater reliability of the assessment tool was measured, there was a range of $70-94 \%$ agreement on all questions between the two evaluators. The kappa score was $>60 \%$ for $85 \%$ of the questions, indicating there was substantial inter-observer agreement [20].

\section{Demographics}

Table 3 describes the demographics of these 134 sites. There was equal representation of profit status, the three regions, and the type of administration. Rural sites were underrepresented in the sample and parent fees were the predominant source of funding for most sites. Urban and for-profit sites were more likely to be predominately statefunded than suburban or non-profit sites. No other differences were detected for the four site subgroup characteristics. Average daily census (ADC) of children varied greatly with a mean of 62 children and a range of 12 to 193 . Most children were preschoolers $(41 \%)$, followed by toddlers $(27 \%)$ and school age children $(24 \%)$. Infants represented $8 \%$ of total enrollment. Table 4 lists the various special health care needs among the children cared for across all the sites combined with the frequency of children with that need and also list the percentage of those children with a written plan.

A site's median time at its current location was 8.25 years with a range of 10 months to $>50$ years; $40 \%$ of the sites had been at their current location less than 5 years. The director's median time in her current position was 2.5 years with a range of 0 months to 23 years; $58 \%$ had less than 3 years experience as the director, and one third had less than one year of experience. Thirty two percent of the providers worked at the site less than one year and $18 \%$ worked less than 6 months.

\section{Practice}

Evaluators assessed the adequacy of the first aid kits and of the 132 with a first aid kit to assess, $71 \%$ were deemed adequate. Seventy percent of 123 centers had an adequate portable first aid kit for off site trips. Staff and child hand washing practices with food and toileting were observed. Of the 114 observations of food preparation and consumption (i.e., not all sites presented the opportunity to observe food preparation and consumption during the on-site evaluation), $88(77 \%)$ of adults and $100(92 \%)$ of children washed their hands. Seventy-eight (83\%) adults and 103 (95\%) children washed after diapering/toileting. Infants' initial sleep position was observed. Of the 205 observations at the 134 sites, staff
Table 3. All Sites: Demographics

\begin{tabular}{|c|c|}
\hline & Number/Percent \\
\hline \multicolumn{2}{|l|}{ Metro Status } \\
\hline Urban & $48 / 36$ \\
\hline Suburban & $67 / 50$ \\
\hline Rural & $19 / 14$ \\
\hline \multicolumn{2}{|l|}{ Profit Status } \\
\hline Nonprofit & $73 / 55$ \\
\hline Profit & $60 / 45$ \\
\hline \multicolumn{2}{|c|}{ Predominant Source of Funding } \\
\hline $67 \%$ state funds & $26 / 19$ \\
\hline $67 \%$ parent fees & $86 / 65$ \\
\hline Neither predominant & $21 / 16$ \\
\hline \multicolumn{2}{|l|}{ Region } \\
\hline Southeast & $46 / 34$ \\
\hline Southwest & $48 / 36$ \\
\hline South-central & $40 / 30$ \\
\hline \multicolumn{2}{|l|}{ Administration } \\
\hline Operates independently & $72 / 55$ \\
\hline Shared administration & $60 / 45$ \\
\hline
\end{tabular}

Table 4. Special Health Care Needs: All Sites Combined

\begin{tabular}{|l|c|c|c|}
\hline Health Care Need & $\begin{array}{c}\# \\
\text { Children }\end{array}$ & $\begin{array}{c}\text { \% } \\
\text { Children* }\end{array}$ & $\begin{array}{c}\text { \% with a Written } \\
\text { Plan }\end{array}$ \\
\hline \hline Allergies & 658 & 8.0 & 32 \\
\hline Asthma & 537 & 6.6 & 39 \\
\hline $\begin{array}{l}\text { Developmental } \\
\text { delay }\end{array}$ & 289 & 3.5 & 24 \\
\hline Behavior problems & 252 & 3.1 & 21 \\
\hline Vision problems & 109 & 1.3 & 9 \\
\hline Seizures & 51 & 0.6 & 18 \\
\hline Motor Problems & 47 & 0.6 & 37 \\
\hline Hearing Problems & 38 & 0.5 & 24 \\
\hline Diabetes & 7 & 0.1 & 86 \\
\hline Other & 19 & 0.2 & 53 \\
\hline Total & 2,077 & 24.6 & 30 \\
\hline *Calculated by dividing the number of children with the specific health care need by
\end{tabular}

*Calculated by dividing the number of children with the specific health care need by the average daily census.

placed $67 \%$ of infants on their backs, $21 \%$ on their stomach, $5 \%$ on their side, and $7 \%$ in some other position, including in a swing or car seat. The evaluators assessed the safety of indoor and outdoor gross motor play areas. For the 32 sites with indoor equipment, safe surfacing under and around the equipment was observed at $10(21 \%)$ sites, $13(28 \%)$ had an adequate fall zone, and $16(50 \%)$ had adequate guardrails. Of 
the 107 sites that had outdoor equipment, safe surfacing was observed under and around the equipment at $52(57 \%)$ of sites, $57(61 \%)$ had an adequate fall zone, and $65(70 \%)$ had adequate guardrails. The outdoor swing fall zone was inadequate at $26(61 \%)$ programs. There was inadequate spacing between equipment for $17(46 \%)$ and $18(22 \%)$ of indoor and outdoor areas, respectively. Greater than $80 \%$ of the programs had adequate maintenance of both indoor and outdoor equipment pieces used for gross motor play.

\section{SUBGROUP ANALYSIS}

The results of our stratified analysis focuses on the statistically significant differences found between the subgroups. Overall, suburban, non-profit, parent funded centers performed better than their counterparts - except for sleep positioning when the opposite association was observed.

\section{Staff Longevity \& First Aid Certification}

Staff longevity was worse at urban sites where only $26(55 \%)$ of the directors had been in their leadership role for more than a year, compared to $21(82 \%)$ suburban directors. Less of the urban childcare staff $(\mathrm{n}=751,67 \%)$ had been at their current job for more than a year compared to their suburban counterparts $(\mathrm{n}=879,75 \%)$. Suburban sites were more likely to have $>50 \%$ of the full time staff first aid certified $93 \%$ vs $71 \%$. Non profit sites were more likely to have $>50 \%$ of the full time staff first aid certified $(92 \% v s$ $75 \%$ ) (see Fig. 1).

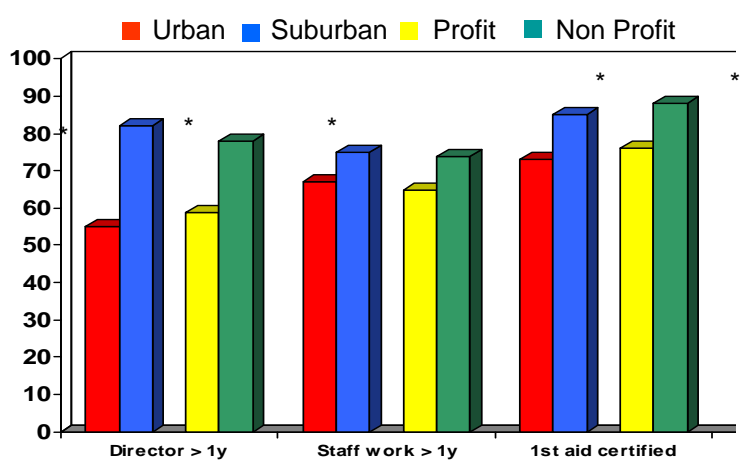

${ }^{*} \mathrm{p}<0.05$

Fig. (1). Staffing: longevity and first aid certification.

\section{Sleep Position}

Placing infants to sleep on their backs is known to reduce the risk of Sudden Infant Death Syndrome (SIDS) by over $40 \%$ [22]. Urban child care providers were more likely to place infants on their back for sleeping when compared to suburban staff $(85 \%$ vs $64 \%, \mathrm{p}<0.005)$. At for profit sites, infants were more likely to be put to sleep on their backs when compared to at non-profit sites $(87 \%$ vs $65 \%, \mathrm{p}<0.005)$. There was no difference noted when comparing state funded vs parent funded sites.

\section{Safe Practices}

Adult hand washing after diapering was better at suburban than urban sites $(86 \%$ vs $72 \%, \mathrm{p}=0.02)$, at parent- funded than state-funded sites $(88 \%$ vs $67 \% \mathrm{p}<0.005)$ and at non-profit sites than for-profit sites $(95 \%$ vs $75 \%, \mathrm{p}=0.02)$. Regarding medication use, 26 (57\%) of urban sites required a physician order compared to $49(75 \%)$ of suburban sites, as well as $32(54 \%)$ of the for-profit sites vs $57(83 \%)$ of the non-profit sites required such. Additionally, 39 (81\%) of the urban sites required parental consent prior to medication use compared to $63(97 \%)$ of suburban sites.

Twenty eight (58\%) urban sites had an adequate first aid kit compared to 50 (77\%) of suburban sites. Of the sites that had indoor play areas, $1(5 \%)$ of the urban sites met standard safety criteria compared to $8(35 \%)$ of suburban sites. Swing safety requires that there is a fall zone that extends 2 times the height of the swing to the floor. Ten $(40 \%)$ urban sites had a safe fall zone compared to $35(67 \%)$ of suburban sites (see Fig. 2).

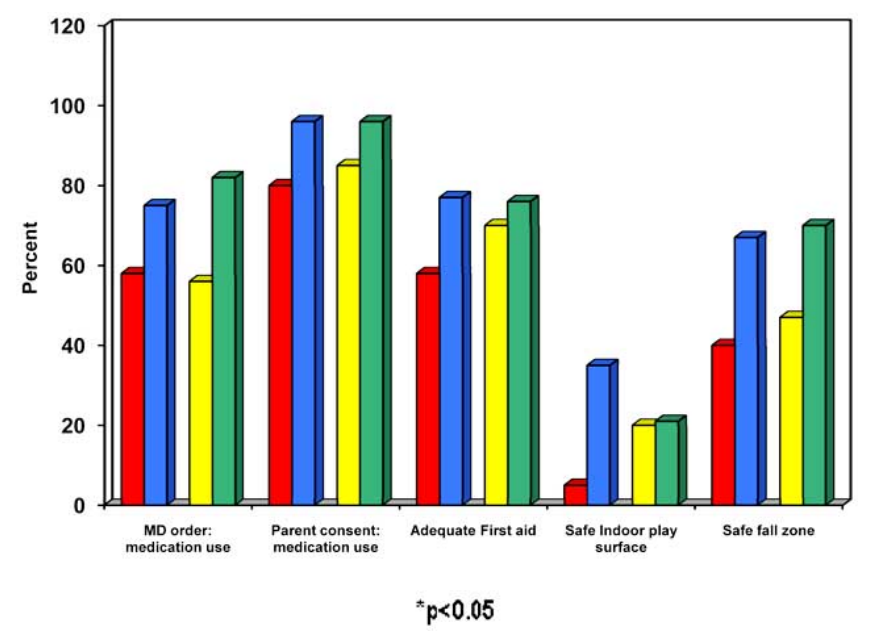

Fig. (2). Policy, procedure \& practice.

\section{DISCUSSION}

Our data shows significant deficiencies in the health and safety practices and policies of child care centers exist and are especially pronounced in urban centers, sites that are predominately state-funded, and for-profit sites.

One reason for these deficiencies may be related to the shortage of experienced directors and providers. Training and consistency of caregivers is a major determinant of center quality $[23,24]$. In our study, we found more than half of the directors had been at their job less than 3 years and almost one-third of the child care providers had been at their position less than 1 year. Low wages, long hours, and work related stress of the child care providers may account for the lack of staff and director longevity. According to the National Association of Child Care Resource and Referral Agencies, in a field where continuity is of primary importance, the child care workforce experiences an annual job turnover rate between 25 and 40 percent [25]. Educational interventions need to be affordable, convenient, and offered at multiple levels intended to accommodate large numbers of new staff, while simultaneously providing learning opportunities to those who make long-term career commitments to early education and child care [25]. With rapid turnover of staff and a relatively short tenure of directors, good health and safety policies are crucial to orient novice staff and help them in maintaining an acceptable standard of 
care. Written policies provide a means of planning and establishing consensus about expected practice. Of course, written policies are ineffective if they are not implemented. Overall, we observed that the staff washed their hands $75 \%$ of the available opportunities. The staff were aware of the observer's presence so this high rate of hand washing may be due to the so called Hawthorne effect that occurs when people are aware of being watched and may not reflect actual hand washing activity that occurs in a busy classroom. Hand washing was less consistent a behavior before food handling than after diapering and for children than adults. Other studies have found that training and periodic observation of hand washing improves staff performance and reduces the incidence of infection in child care settings [26, 27]. Studies of infectious disease in child care confirm the increased risk of illness related to group care [28-30]. Age-appropriate immunization and hygiene practices lower the risk of infection, especially when appropriate hand washing follows contamination of hands by contact with body fluids or soil and occurs before activities involving food [31]. Most recently, Kotch, and colleagues of North Carolina, conducted a study of 23 pairs of CCCs looking at the installation of diaper-changing, hand washing and food preparation equipment and concluded that specifically designed diapering, hand washing and food preparation equipment reduced diarrheal illness among the CCCs' children and reduced out-of-home CCC staff absences as a result illness [16]. Similar to Moon's study of child care provider self-reported sleep positioning of infants in their care, we found that $1 / 3$ of infants were directly observed to be improperly placed in some position other than on their backs to sleep at child care centers. Twenty percent of SIDS occurs in childcare settings [32]. While the etiology of SIDS is still unclear, prone or side sleep position, and soft bedding play a significant role [33]. Recent data on infant sleep positioning in child care suggests that providers may be increasing the risk of SIDS deaths in this setting by failing to adopt back-only sleeping policies [34-36]. Barriers to use of proper positioning are being explored to determine how to overcome unsafe sleep positioning. Providers have cited parental request as the most common reason for prone sleeping [37]. Educating directors and staff regarding SIDS has improved caregiver knowledge, selfreported and observed behavior and drafting of safe sleep policies [22, 38, 39].

Our on site evaluation revealed poor compliance with safety measures recommended for active (gross motor) play, especially for indoor equipment. Since the most frequent and severe injuries occur in areas where children play on climbing equipment over hard surfaces, it is especially concerning that we found so few sites had safe surfacing and adequate fall zones indoors and outdoors. Although injury rates are lower for children in child care centers than in family child care homes or in the children's own homes, most of these injuries are preventable. In a different study by Kotch, and colleagues, of North Carolina CCCs, the authors showed a decrease in medically attended injuries that were temporally associated with institution of improved state regulations for playground safety. As in our study, they found that the under surfacing and fall zones were inadequate at many sites [40]. Indoor safety hazards did not show improvement in Kotch's study. This may reflect the lack of awareness among providers of the risks, and insufficient regulatory control of hazards in indoor and outdoor areas used for gross motor play. Urban, predominately state-funded, for-profit centers consistently perform worse on most important health and safety policies and practices. It is likely that low income and disadvantaged children predominately attend such centers. This is unfortunate as they are the children who may receive the most benefit from high quality child care. Quality improvement activities should include better surveillance and interventions to reduce risky practices and hazards as well as targeted funding of interventions to the neediest sites.

Many states are adopting Early Learning Standards with references to health, acknowledging that health and safety are key components for ensuring school readiness. In January 2008, The National Resource Center for Health and Safety in Child Care developed a Toolkit for Integrating Healthy Physical and Mental Development in Early Learning Guidelines based on an assessment of the Early Learning Standards of 10 states [41]. For 15 key health and safety topics, the toolkit illustrates the relationship between the state early learning standards and Caring for Our Children, the national health and safety standards, citing examples from the 10 states [9]. The National Resource Center (NRC) for Health and Safety in Child Care and Early Education created this Toolkit to help state/territorial teams evaluate and supplement their ELG content related to children's healthy physical and mental development [41]. Each state should link their Early Learning Standards with the national health and safety performance standards, and then adopt measures to achieve quality in health and safety performance as an integral component of their quality improvement activities. The greatest need for improvement was observed in urban, forprofit centers that are predominately state-funded. Early educators need professional development, technical assistance, and ongoing relationships with health professionals to meet the national standards for health and safety. A 2006 report by the National Healthy Child Care Consultant Network Support Center emphasizes the outcomes and impact of health professionals working with early learning programs [42]. Quality improvement interventions that include a Child Care Health Consultant (CCHC) element were found to improve overall child care quality and school readiness [41, 42]. Consistent findings across multiple studies show these positive outcomes:

- Improved written health policies that are consistent with Caring for Our Children [9]

- Prevention of communicable disease and reduced days absent for illness

- Improved observed health and safety practices such as hand washing, diapering, active play, nutrition and food handling

- $\quad$ Reduced risk of Sudden Infant Death Syndrome (SIDS) through targeted training about infant sleep positioning and the sleep environment

- Increase documentation of children with up-to-date immunizations and a regular source of medical care for preventive and treatment health services 
- Increased social skills and behavior management through the use of mental health consultants [42].

Twenty-nine states now mandate child care health consultant visits for early education and child care. This requirement is included in the center accreditation criteria of the National Association for the Education of Young Children and has been part of the military child care system for decades.

\section{LIMITATIONS}

Since our study is limited to 134 regulated child care centers that volunteered to participate, our findings may not apply proportionately to all types of care. It is possible that these were low-performing centers where the staff knew they needed help. We suspect that the volunteered centers may represent the better functioning centers in our state because they indicated their inclination toward self-improvement. Our decision to use volunteer evaluators and to recruit centers from the three most populous areas of the state was based on the presumption that the interventions would improve child care center performance and engage more health professionals in this work across the state. Additionally, our observations of hand washing and sleep position practices may not reflect actual practice when staffs are not being observed. We suspect that actual practice may be worse than what occurs when the staff knows they are being observed.

\section{CONCLUSION}

The data shows significant hazards and risky practices may be commonplace in regulated early education and child care programs. Improving the training of staff, drafting of policies, and obtaining input from skilled health professionals have a growing body of evidence that shows how taking these steps promote safer and healthier care centers [42].

\section{ACKNOWLEDGEMENTS}

The work of this project was supported by the federal Maternal Child Health Bureau (MCHB) Grant \# 1 H34 MC 00032-01 and administered by a contract between the Pennsylvania Chapter of the American Academy of Pediatrics (PA AAP) and the Pennsylvania Department of Health Contract \# ME 99118; additional support was provided by Jewish Health Care Foundation. The authors express gratitude to Marlene Moulder for tireless assistance with manuscript preparation.

\section{REFERENCES}

[1] ChildStats.gov. Forum on Child and Family Statistics. Child Care: Percentage of Children Ages 0-6, not yet in Kindergarten by Type of Care Arrangement and Child and Family Characteristics, 1995,2002, 2005. www.childstats.gov/americaschildren/tables/fam 3b.asp [Accessed January 13, 2010].

[2] U.S.National Center for Education Statistics. The Condition of Education 2002 (NCES 2002-025). Washington, DC: U.S. Government Printing Office, US Department of Education. www.nces.ed.gov/pubs2009/2009081.pdf [Accessed January 13, 2010].

[3] Gomby DS, Larner MB, Stevenson CS, Lewit EM, Behrman RE. Longterm outcomes of early childhood programs: analysis and recommendations. Future Child 1995; 5: 6-24.

[4] Peisner-Feinberg ES, Burchinal MR, et al. The relation of preschool child-care quality to children's cognitive and social developmental trajectories through second grade. Child Dev 2001; 72(5): 1534-53.
Scott-Little C, Kagan SL, Frelow VS. Standards for preschool children's learning and development: Who has the standards, how were they developed, and how were they used? Greensboro, North Carolina: University of North Carolina, SERVE. 2003 www.serve. org/TT/Early\%20Learning\%20Standards.pdf [Accessed January 12, 2010].

[6] Pennsylvania Department of Education. Standards, Curriculum and Assessment for Early Childhood Education, 2007.(www. pde.state. pa.us/early childhood/cwp/view.asp?Q $=101706$ [Accessed on February 25, 2010].

[7] Helburn SW, Howes C. Child care cost and quality. Future Child 1996; 6: 62-82

[8] Fiene R, Greenberg M, Bergsten M, Carl B, Gegley C, Gibbons E. The Pennsylvania Early Childhood Quality Settings Study, November 2002. Keyword: Early Care and Education and www.ecti.hbg.psu.edu/ucpc/docs/ecqs_report_present_n2b_mb.ppt \#256,1 The Pennsylvania Early Childhood Quality Settings Study [Accessed January 12, 2010].

[9] American Academy of Pediatrics, American Public Health Association, and National Resource Center for Health and Safety in Child Care. Caring for Our Children: National Health and Safety Performance Standards: Guidelines for Out-of-Home Child Care Programs, $2^{\text {nd }}$ ed. Elk Grove Village, IL: American Academy of Pediatrics and Washington, DC: American Public Health Association. 2002 www.nrckids.org/CFOC/PDFVersion/ National $\% 20$ Health $\% 20$ and $\% 20$ Safety $\% 20$ Performance $\% 20$ Standa rds.pdf [Accessed January 12, 2010].

[10] 2004 CFR Title 45-Public Welfare, Chapter XIII- Office of Human Development Services Department of Health and Human Services, Part 1304 -Program Performance Standards for the Operation of Head Start Programs by Grantee and Delegate Agencies. www.head-start.lane.or.us/administration/regulations/45CFR130x.ind ex.html [Accessed January 12, 2010].

[11] NAEYC Accreditation available at www.naeyc.org, key word Accreditation. http: //www.naeyc.org/store/node/350 [Accessed January 12, 2010].

[12] Briss PA, Sacks JJ, Addiss DG, Kresnow M, O'Neil J. A nationwide study of the risk of injury associated with day care center attendance. Pediatrics 1994; 93: 364-8.

[13] Addiss DG, Sacks JJ, Kresnow MJ, O'Neil J, Ryan GW. The compliance of licensed US child care centers with national health and safety performance standards. Am J Public Health 1994; 84: 11614.

[14] Aronson S.S. Aiken L.S. Compliance of child care programs with health and safety standards: impact of program evaluation and advocate training. Pediatrics 1980; 65: 318-25.

[15] Alkon A, Sokal-Gutierez K, Wolff M. Child care health consultation improves health knowledge and compliance. Pediatr Nurs 2002; 28: $61-5$

[16] Kotch JB, Isbell P, Weber DJ, et al. Hand-Washing and Diapering Equipment Reduces Disease Among Children in Out-of Home Child Care Centers. Pediatrics 2007; 120(1): e29-36.

[17] National Fire Prevention Association. Risk Watch ${ }^{\circledR}$, a school-based injury prevention program in five age-appropriate teaching modules. Pre-K/Kindergarten module, addressing 8 injury topics. NFPA. Battery March Park, MA http: //www.nfpa.org/category List.asp? categoryID $=1050 \& U R L=$ Safety\%20Information/For\%20 public\%20educators/Education\%20programs/Risk\%20Watch $®$ [Accessed January 12, 2010].

[18] National Center for Health and Safety in Child Care. Stepping Stones to Using Caring for Our Children, $2^{\text {nd }}$ ed. 2003 www.nrc. uchsc.edu/STEPPING/index.htm [Accessed January 13, 2010].

[19] Healthy Child Care Pennsylvania. Pennsylvania Chapter American Academy of Pediatrics. Model Child Care Health Policies, $4^{\text {th }}$ ed. PA AAP, 2004. Available in print from NAEYC, Washington, DC.. www.ecels-healthychildcarepa.org/content/MHP 4thEd\%20Total.pdf [Accessed January 13, 2010].

[20] Landis J, Koch GG. The measurement of observer agreement for categorical data. Biometrics 1977; (33): 159-74.

[21] Lagakos SW. The challenge of subgroup analyses--reporting without distorting erratum. N Engl J Med 2006; 354(16): 1667-9. (erratum appears in N Engl J Med.2006; 355(5): 533.

[22] American Academy of Pediatrics. The Changing Concept of Sudden Infant Death Syndrome: Diagnostic Coding Shifts, Controversies Regarding. the Sleeping Environment, and New Variables to 
Consider in Reducing Risk. Task Force on Sudden Infant Death Syndrome. Pediatrics 2005; 116: 1245-55.

[23] Aronson SS. Child care and the pediatrician. Pediatr Rev 1989; 10, $277-86$.

[24] Aronson SS. Role of the pediatrician in setting and using standards for child care. Pediatrics 1993; 91: 239-43.

[25] National Association of Child Care Resource \& Referral Agencies (NACCRRA) www.naccrra.org/randd/child-care-workforce/cc_wo rkforce.php [Accessed January 13, 2010].

[26] Roberts L, Jorm L, Patel M, SmithW, Douglas RM, McGilchrist C. (2000). Effect of infection control measures on the frequency of diarrheal episodes in child care: a randomized, controlled trial. Pediatrics 2002; 105(4 Pt 1), 743-6.

[27] Roberts L, Smith W, Jorm L, Patel M, Douglas RM, McGilchrist C. (2000). Effect of infection control measures on the frequency of upper respiratory infection in child care: a randomized, controlled trial. Pediatrics 2002; 105(4 Pt 1): 738-2.

[28] Bradley RH. National Institute of Child Health and Human Development (NICHD)Early Child Care Research Network. Child care and common communicable illnesses in children aged 37 to 54 months. Arch Pediatr Adolesc Med 2003; 157: 196-200.

[29] Schwartz B, Giebink GS, Henderson FW, Reichler MR, Jereb J, Collet JP. Respiratory infections in day care. Pediatrics 1994; 94: 1018-20.

[30] Wald ER, Dashefsky B, Byers C, Guerra N, Taylor F. Frequency and severity of infections in day care. J Pediatr 1998; 112(4): 540-546.

[31] Niffenegger J. Proper handwashing promotes wellness in child care. J Pediatr Health Care 1997; 11:26-31.

[32] Moon RY, Biliter WM, Croskell SE. Examination of state regulations regarding infants and sleep in licensed child care centers and family child care settings. Pediatrics 2001; 107(5): 1029-36.
[33] American Academy of Pediatrics. Does bed sharing affect the risk of SIDS? American Academy of Pediatrics. Task Force on Infant Positioning and SIDS. Pediatrics 1997; 100(2 Pt 1): 272.

[34] Ford KM, Linker LA. Compliance of licensed child care centers with the American Academy of Pediatrics/ recommendations for infant sleep positions. J Commun Health Nurs 2002; 19(2): 83-91.

[35] Moon RY, Patel KM, Shaefer J. Sudden infant death syndrome in child care settings. Pediatrics 2000; 106: 295-300.

[36] Gershon NB, Moon RY. Infant sleep position in licensed child care centers. Pediatrics 1997; 100(1): 75-8.

[37] Moon RY, Biliter WM. Infant sleep position policies in licensed child care centers after back to sleep campaign. Pediatrics 2000; 106(3): 576-80.

[38] Moon RY, Sprague B, Patel K. Prevalence but changing risk factors for Sudden Infant Death Syndrome in child care settings in 2001. Pediatrics 2005; 116: 972-7.

[39] Moon RY, Calabrese T, Aird L. Death syndrome in child care and changing provider practices: lessons learned from a demonstration project. Pediatrics 2008; 122: 788-98.

[40] Kotch JB, Hussey JM, Carter A. Evaluation of North Carolina child care safety regulations. Injury Prevention 2003; 9: 220-5.

[41] National Resource Center for Health and Safety in Child Care and Early Education. Toolkit for Integrating Healthy Physical and Mental Development in Early Learning Guidelines. www.nrc.uchsc.edu/ELG/elg.htm [Accessed January 13, 2010]

[42] Ramler M, Nakatusukasa-Ono W, Loe C, Harris K. The Maternal and Child Health Bureau, Health Resources Services Administration. . The Influence of Child Care Health Consultants in Promoting Childrens Health and Well-being: A Report on Selected Resources. The Health Child Care Consultant Network. 2006. www.hccensc.jsi.com/resources/publications/CC_lit_review_Scree n_All.pdf [Accessed January 13, 2010].

(C) Nadel et al.; Licensee Bentham Open.

This is an open access article licensed under the terms of the Creative Commons Attribution Non-Commercial License (http://creativecommons.org/licenses/by$\mathrm{nc} / 3.0 /$ ) which permits unrestricted, non-commercial use, distribution and reproduction in any medium, provided the work is properly cited. 